\title{
Retrospective: Mammoplasty with Prosthesis after Video-Assisted Bariatric Surgery with Transverse Bipediculated Flap*
}

\author{
José Humberto Cardoso Resende ${ }^{1}$, Rossano Kepler Alvim Fiorelli ${ }^{2}$ \\ ${ }^{1}$ Plastic Surgery, Federal Hospital for the Civil Servants of the State of Rio de Janeiro, Rio de Janeiro, Brazil; ${ }^{2}$ General Surgery, \\ Federal University of the State of Rio de Janeiro, Rio de Janeiro, Brazil. \\ Email: jresen99@hotmail.com
}

Received August 23 ${ }^{\text {rd }}, 2013$; revised September 21 ${ }^{\text {st }}$, 2013; accepted September $28^{\text {th }}$, 2013

Copyright (C 2013 José Humberto Cardoso Resende, Rossano Kepler Alvim Fiorelli. This is an open access article distributed under the Creative Commons Attribution License, which permits unrestricted use, distribution, and reproduction in any medium, provided the original work is properly cited.

\begin{abstract}
Objective: To assess the rate of mammary prosthesis extrusion after mammoplasty with prosthesis implantation, to verify the resulting shape and the degree of patient satisfaction after the use of a transverse bipediculated flap with lateral irrigations. Methods: 30 patients with a weight loss of $50 \mathrm{~kg}$ on average after video-assisted bariatric surgery, with ptosis and excessive volumes, who underwent mammoplasty with prosthesis placement with volumes ranging from 190 to 260 cc, using a transverse flap with the aim of anchoring the silicone prosthesis. Results: In the patients' evaluation, the few postoperative complaints did not amount to complications. Pains were minimal and the discomfort with the prosthesis was acceptable. Conclusion: the transverse flap, in addition to acting as the best anchor among the existing flaps for implanted prostheses, provided a youthful, natural, anatomical, aesthetic and longer lasting appearance for the breasts.
\end{abstract}

Keywords: Mammoplasty; Mastoplasty with Prosthesis; Non-Aesthetic Female Mammary Plastic Surgery; Post-Bariatric Mammoplasty

\section{Introduction}

This study of transverse flaps in mammoplasties was guided by an assessment of results in order to decrease the rate of extrusion of mammary prostheses used to give the breasts a better shape, lifting them up to place them in a better anatomical position, with a better shape and consistency, reducing the number of repeat operations or a constant exchange of prostheses [1].

Patients who undergo bariatric surgery lose weight in a short time [2], causing tissue to sag, primarily that of the skin, causing esthetic, interpersonal problems and low self-esteem [3].

The transverse flap is irrigated at the medial portion by branches of the internal thoracic or mammary arteries, and on the lateral portion by branches of the external thoracic and axillary arteries. With the detachment of the upper pectoralis major in order to form a pocket where the prosthesis will be placed, the flap receives little irri-

*Final monograph for the professional master’s degree in medicine. gation from intercostal arteries [4].

Other techniques may serve the same purpose [5], but the transverse flap provides the prosthesis safety and protection against possible extrusions, which could occur at the joint of the inverted "T" scar without the flap.

Thus, this study aimed at evaluating and demonstrating a new technique that removes excess skin due to large weight loss using the transverse flap to protect the placement of the silicone prosthesis.

\section{Method}

For this study, we selected 30 patients that had undergone video-assisted bariatric surgery, aged between 30 and 55 years, regardless of color, religion or other options, all with a weight loss above $30 \mathrm{~kg}$. They were operated after six (6) months of weight maintenance and a minimum of two (2) years after bariatric surgery.

They attended the Workshop for the Obese, which supervises the nutritional aspect, answers all questions relative to the necessary plastic surgeries, assuring patients 
and boosting the will power of candidates for body repair.

The proposed surgery consists in marking the inverted "T" technique in final form. Points A-D and E (Figure 1) are previously marked [6] and the entire area is included within the markings to be decorticated, thus taking advantage of all existing tissues except the skin. The anesthetic infiltration is carried out along the entire marking route (Figure 2). Next, the marking is performed with an Areola \& Keyhole Marker (Figure 3). After decortication, hemostasis and marking of the superior flap (Figure 4), the detachment above the pectoralis major is performed, for placement of the prosthesis (Figure 5). Then the superior flap is released, maintaining the medial pedicle larger than the lateral one to irrigate the areolas, separating the superior flap that contains the areolar-papillary complex of the transverse flap ready and freed. After inserting the prosthesis [7], the flap's inferior base is attached to the pectoralis major fascia $5 \mathrm{~cm}$ above the bottom edge of the inverted "T" (Figure 6). All blood tissues are approximated (Figure 7). Finally, the skin is sutured and the areolar-papillary complex is reimplanted (Figure 8). Stitches are made with intradermally absorbable sutures. The patient is released in 24 hours; revisions are made twice a week until the second month, and monthly monitoring is carried out for six (6) months. (Figures 9-16 show a retrospective of pre- and postoperative phases of used techniques).

An assessment instrument was developed and applied at the end of the sixth month after surgery, to which all patients responded subjectively, with 0-10 scores, where the highest number represents greater satisfaction with the surgery's outcome (Figure 17).

\section{Results}

When the surgeries were evaluated, it was found that postoperatively there is greater hardening of the breasts, without capsular contracture of the prostheses. Less descensus (natural drooping or sagging of the breast with

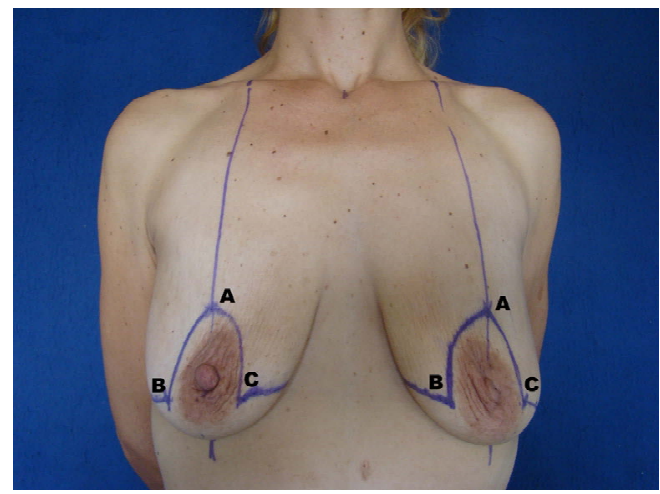

Figure 1. Pre-operational stage with technique's markings.

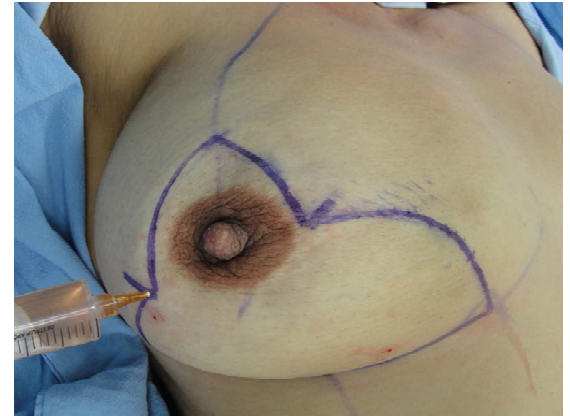

Figure 2. Infiltration of incisions.

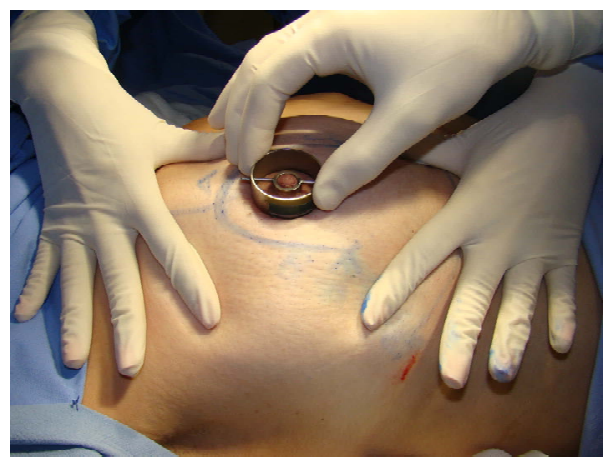

Figure 3. Marking of the areolar-papillary complex.

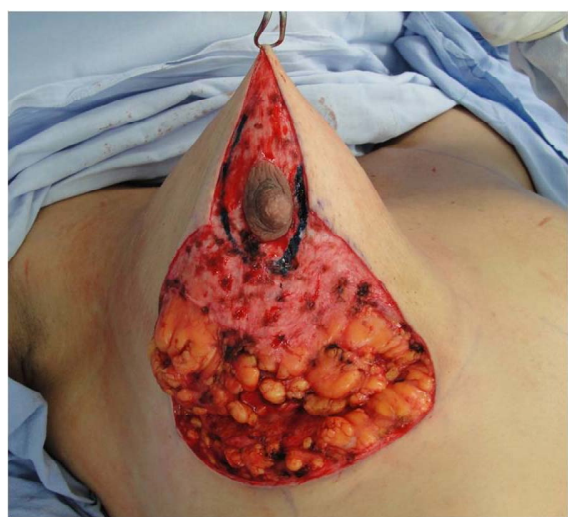

Figure 4. Decortication, hemostasis and marking of the superior flap.

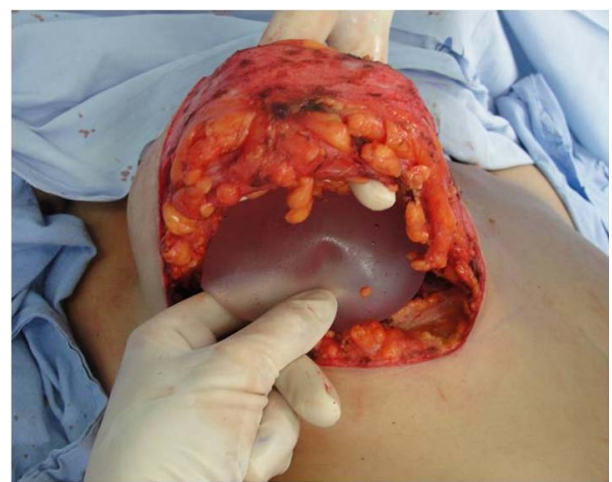

Figure 5. Placement of silicone prosthesis. 


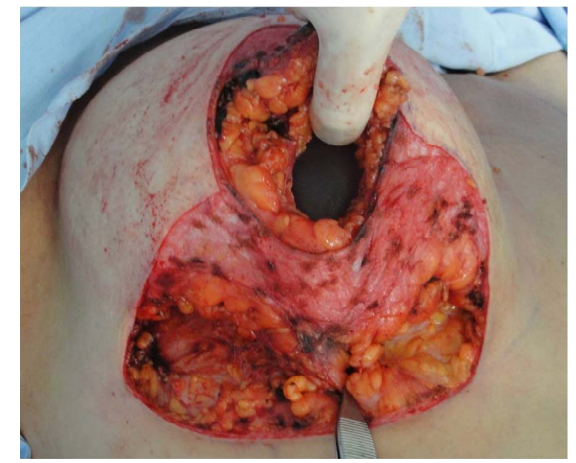

Figure 6. Fixation of transverse flap in the fascia of the pectoralis major.

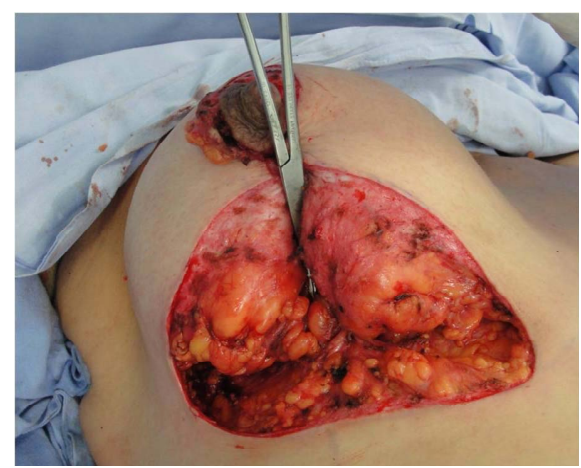

Figure 7. Approximation of blood tissues.

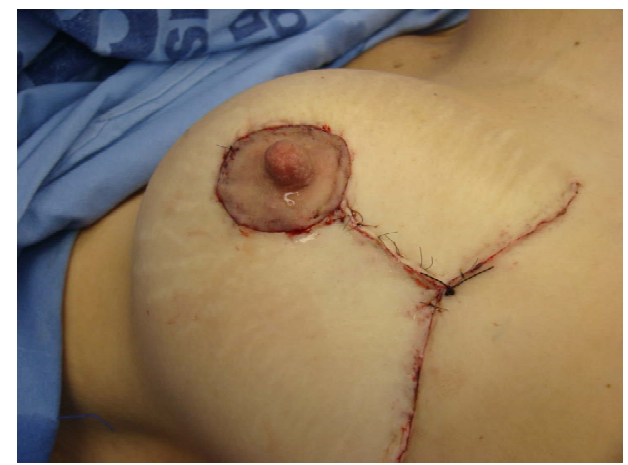

Figure 8. Reimplantation of the areolar-papillary complex.

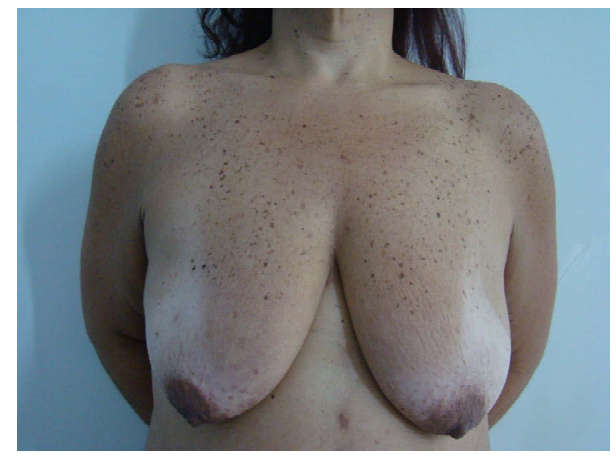

Figure 9. Pre-operational stage front-patient A. T., 35 years of age and weight loss of $55 \mathrm{~kg}$.

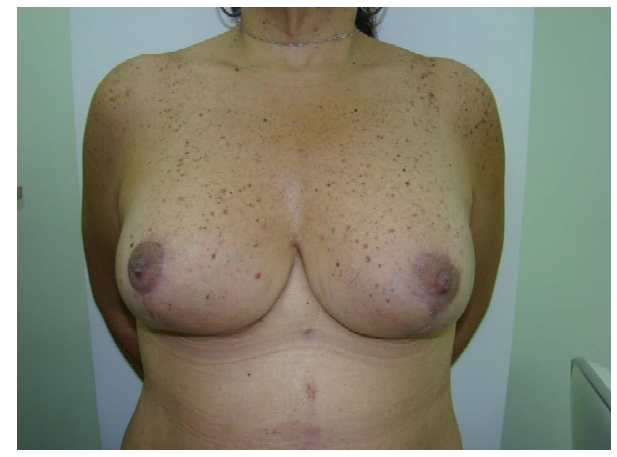

Figure 10. Post-operational stage front after 6 months, patient A. T.

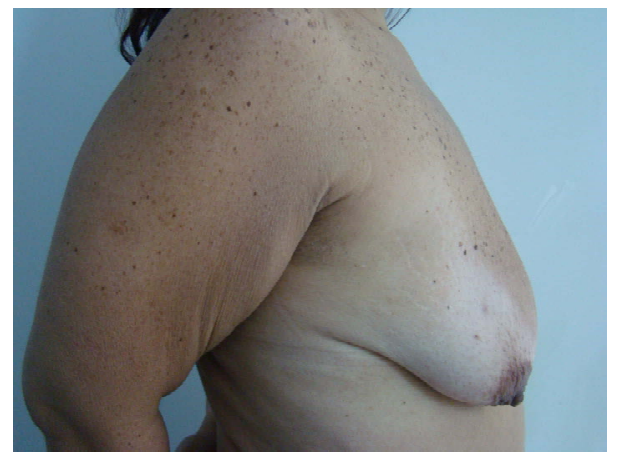

Figure 11. Pre-operational stage profile-patient A. T.

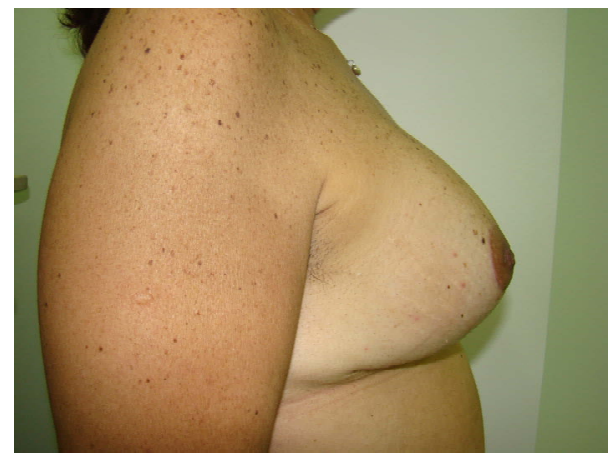

Figure 12. Post-operational stage profile after 6 months, patient A. T.

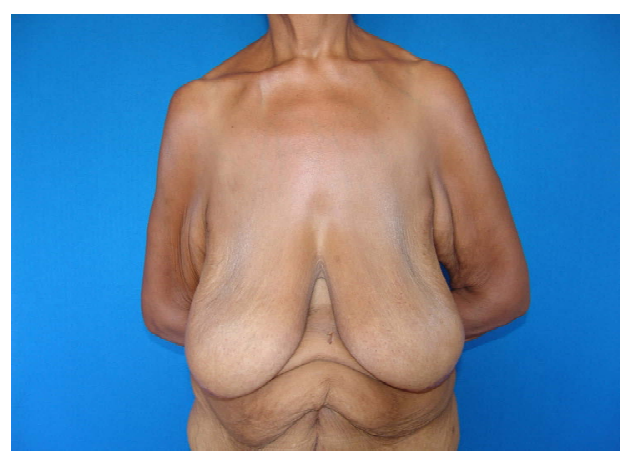

Figure 13. Pre-operational stage front-patient M. S. 52 years of age and weight loss of $62 \mathrm{~kg}$. 


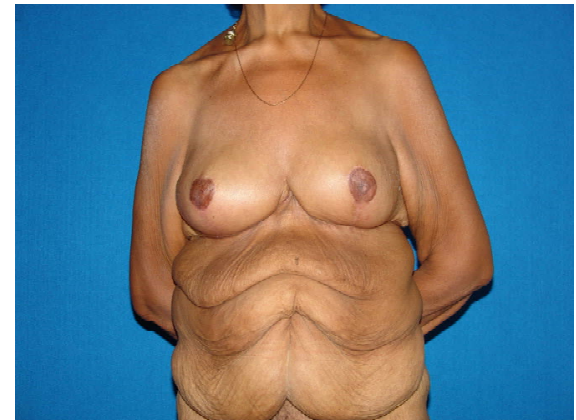

Figure 14. Post-operational stage front after 6 months, patient M. S.

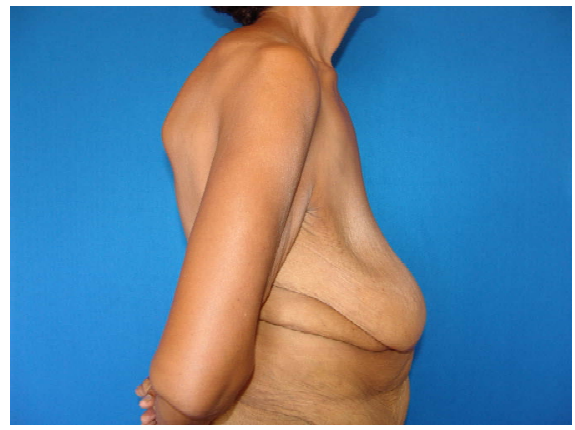

Figure 15. Pre-operational stage profile-patient M. S.

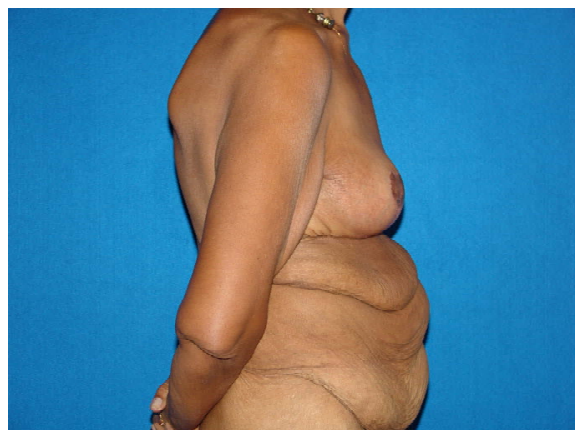

Figure 16. Post-operational stage profile com 6 after 6 months, patient M. S.

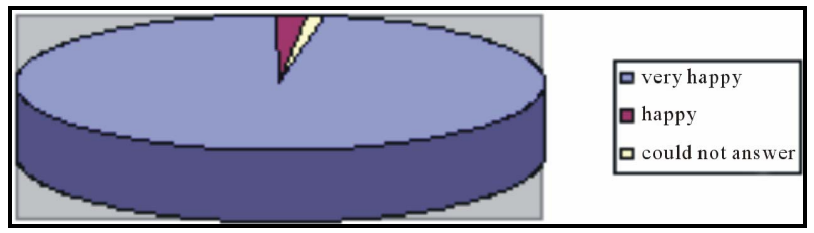

Figure 17. Graph representing degree of satisfaction in percentage points.

time) was also observed than with other techniques that have been used [8]. No cases of prosthetic extrusion were found [9]. The surgeries were performed in less than three hours. As the scars are smaller, the degree of satisfaction was excellent and social reintegration was complete. Thus, $97 \%$ of patients responded that they were happy and evaluated their satisfaction with 10 points. $2 \%$ answered that they were happy, but still expected more plastic surgeries in the rest of their bodies. $1 \%$ could not answer, despite being happy with the surgery performed.

\section{Discussion}

In patients who lost weight as a result of bariatric surgery, there is distress and psychological discomfort resulting from excess skin that exhibits excessive ptosis of the breasts and all other parts of the body [3]. The flaccidity is so severe that whatever the selected technique the breasts will not be anatomical without the placement of silicone breast implants since they have no glandular volume [10]. There is a large difference between those who have lost weight of their own free will, losing $30 \mathrm{~kg}$, and patients with a weight loss of over $50 \mathrm{~kg}$ for example [10]. With bariatric surgery, weight loss is not protracted, it takes place gradually, but at a much faster rate. It has also been noted that the flaccidity is permanent, leading surgeons to select techniques that remove far more skin than cellular tissue, in order not to induce major detachments [11]. In the long run, after bariatric surgery, no mammoplastic technique will meet patients' desire to possess hardened breasts, with anatomical and durable shapes. The flap with inferior pedicle [12] used in mammoplasties has shown to be a great surgical option with excellent results. However, this work [13] does not describe its use in post-bariatric breast surgery where ptosis has become extremely severe tending to impermanent results. On the other hand, flaps with superior pedicle [4] are best used in reduction mammoplasties, not specifically for post-bariatric cases. Mastopexy cases have been reported with superior pedicle flaps and silicone implants with only $7.35 \%$ of cases with ptosis reincidence [9], which is considered an excellent result. Inferior flaps described as dermal pyramids [14] are another option for good aesthetic results, when resections were between 200 gr to 3350 gr in each breast. It must be pointed out that, in evaluations, there was one case of a free graft detached from the areolar-papillary complex, owing to the long distance between the areolar complex and point "A" for reimplantation. Thus, possible tissue sufferance or even necrosis are avoided [15]. The relevance of using flaps to improve mammal symmetry, including post-mastectomy cases due to cancer, was verified [2]. It also provides an option for the use of the thoracic wall flap in vertical mammoplasties [16]. The best indications are for cases of reductive mammoplasties, whereas it may not apply to post-bariatric surgery cases, owing to the excess skin and little glandular tissue to be removed. In all cases, in this retrospective, the placement of silicone tape on scars was advised for the prevention of keloids.

The transverse bipediculated flap presented in this 
study was performed to serve as an anchor belt for the silicone prostheses implanted, preventing its extrusion, thereby improving the shape of the breast and making the result longer lasting.

\section{Conclusion}

Comparing cases and reviewing the literature, we conclude that the transverse bipediculated flap used in postbariatric surgery of mammoplasty mastopexy cases will be another option for the surgeon, in view of the challenges that deformities pose to us. In our retrospective review, the good shape exhibited by the breasts, minimal complications, such as ecchymosis and erythema, and no cases of prosthesis extrusion were noted. It also demonstrated that the flap can be used in mastopexy cases to correct ptosis, even if not caused by post-bariatric surgery slimming.

\section{Acknowledgements}

To Prof. Dr. Rossano Kepler Alvim Fiorelli, UNIRIO M.Sc. supervisor, to Paulo Marcos Queiroz Resende and Filipe Algayer Casagrande for their collaboration.

\section{REFERENCES}

[1] R. Baroud and J. R. Lewis, "The Augmentation-Reduction Mammoplasty,” Clinics in Plastic Surgery, Vol. 3, No. 2, 1976, pp. 301-308.

[2] D. S. B. Nassif, O. Malafaia, P. A. N. Nassif, C. H. Kuretzki, R. W. C. Lucas and J. S. P. Pinto, "Protocolo Eletrônico Multiprofissional em Cirurgia Bariátrica,” Arquivos Brasileiros de Cirugia Digestiva, Vol. 24, No. 3, 2011, pp. 215-218. http://dx.doi.org/10.1590/S0102-67202011000300007

[3] C. B. Okano, H. B. Giampietro and G. A. N. Almeida, “Tratado de Cirurgia Plástica na Obesidade,” Ed. Rubio, 2008, pp. 87-104.

[4] P. K. McKissock, "Reduction Mammoplasty with a Vertical Dermal Flap,” Plastic and Reconstructive Surgery, Vol. 49, No. 3, 1972, pp. 245-252. http://dx.doi.org/10.1097/00006534-197203000-00001

[5] G. Peixoto, "Reduction Mammoplasty: A Personal Technique,” Plastic and Reconstructive Surgery, Vol. 65, No. 2, 1980, pp. 217-226.

\section{http://dx.doi.org/10.1097/00006534-198002000-00015}

[6] I. Pitanguy, "Surgical Treatment of Breast Hypertrophy," British Journal of Plastic Surgery, Vol. 20, 1967, pp. 7885. http://dx.doi.org/10.1016/S0007-1226(67)80009-2

[7] O. R. Saldanha, "Mamaplastia Redutora com Implante de Silicone," Revista Brasileira de Cirurgia Plástica, Vol. 25, No. 2, 2010, pp. 317-324.

[8] F. J. F. Bezerra, R. M. G. Moura and V. V. Silva Junior, "Mamaplastia Redutora e Simetrização de Mama Oposta em Reconstrução Mamária Utilizando a Técnica de Pedículo Inferior,” Revista Brasileira de Cirurgia Plástica, Vol. 22, No. 1, 2007, pp. 52-59.

[9] R. S. Gomes, "Mastopexia com Retalho de Pedículo Superior e Implante de Silicone,” Revista Brasileira de Cirurgia Plástica, Vol. 23, No. 4, 2008, pp. 241-247.

[10] J. H. C. Resende, "Tratado de Cirurgia Plástica na Obesidade,” Ed. Rubio, 2008, pp. 377-380.

[11] J. L. Leal, M. Nahon, F. Manoel and A. S. Melo, "Dermolipectomia Abdominal com Cicatriz Suprapúbica," Tratado de Cirurgia Plástica na Obesidade, Ed. Rubio, 2008, pp. 286-290.

[12] L. Ribeiro, "A New Technique for Reduction Mammaplasty,” Plastic and Reconstructive Surgery, Vol. 55, No. 3, 1975, p. 330.

[13] W. H. M. O. Wallace, W. O. B. Thompson, R. A. Smith, K. R. Barbosa, S. F. Davidson, J. T. H. Thompson, S. Thompson and K. R. Barreza, "Reduction Mammoplasty Using the Inferior Pedicle Technique,” Annals of Plastic Surgery, Vol. 40, No. 3, 1998, pp. 235-240. http://dx.doi.org/10.1097/00000637-199803000-00007

[14] G. S. Georgiade, R. E. Riefkohl and N. G. Georgiade, "The Inferior Dermal-Pyramidal Type Breast Reduction: Long-Term Evaluation,” Annals of Plastic Surgery, Vol. 23, No. 3, 1980, pp. 203-211.

[15] M. Lacerna, J. Spears, A. Mitra, C. Medina, E. McCampbell and R. Kiran, “Avoiding Free Nipple Grafts during Reduction Mammoplasty in Patients with Gigantomastia,” Annals of Plastic Surgery, Vol. 55, No. 1, 2005, pp. 21-24. http://dx.doi.org/10.1097/01.sap.0000168249.09491.21

[16] R. Graf, L. R. R. Araujo, R. Rippel, L. G. Neto and D. P. Biggs, "Mamaplastic Vertical com Retalho De parede Torácica,” Revista Brasileira de Cirurgia Plástica, Vol. 20, No. 3, 2005, pp. 148-154. 